\title{
HUMANIDADES Y EDUCACIÓN: EL PAPEL DE LA CRÍTICA $^{1}$
}

\author{
Carlos Ruiz Schneider \\ Departamento de Filosofía \\ Universidad de Chile
}

Me propongo tratar el tema de Humanidades y educación, limitándome, en primer lugar a la Universidad, y luego, a algunos aspectos que tienen que ver con el sistema educacional en general.

Argumentaré brevemente en lo que sigue, en favor de la necesidad de una presencia muy significativa de las humanidades en el currículo universitario y escolar, y por eso mismo también en la formación de los futuros maestros.

Abordaré el tema a partir de los trabajos de dos filósofas norteamericanas contemporáneas, Amy Gutmann y Martha Nussbaum, cuyos escritos sobre las humanidades, la filosofía y la educación me parecen notables.

En un brillante artículo de 1982 titulado “¿Para qué sirve ir a la escuela? El problema de la educación en las teorías utilitarias y las teorías de los derechos", publicado en un célebre libro colectivo sobre el utilitarismo editado por Amartya Sen y Bernard Williams, la filósofa estadounidense Amy Gutmann se propone analizar cómo se justifica la educación para las dos filosofías políticas liberales más importantes en el mundo anglo sajón, el utilitarismo y las teorías de los derechos al estilo de John Rawls o Ronald Dworkin.

1 Discurso inaugural Escuela de Postgrado, Facultad de Filosofía y Humanidades, Universidad de Chile, Santiago 2010. 
Propone como marco general de su investigación la idea de que las teorías utilitarias tienen como concepto central el de felicidad, mientras que las teorías de los derechos remiten al concepto de libertad.

Ambos paradigmas, señala Gutmann, concebidos de una manera muy sesgada: la felicidad, entendida como maximización de utilidades a través de un cálculo de costos y beneficios, y la libertad, entendida a la manera neo-liberal, como una libertad sin trabas para los individuos y los grupos de escoger y de fundar establecimientos educacionales sin intervención de la comunidad política, se han utilizado en Chile para justificar un rol preponderante del mercado en educación, especialmente en la educación superior, como lo subrayan muchos de los informes sobre la educación chilena, en especial los de la OECD, e incluso el Banco Mundial ${ }^{2}$.

Para ilustrar los resultados que tiene aplicar la mirada utilitaria, Amy Gutmann cita algunos textos de Jeremy Bentham y de James Mill, los fundadores del utilitarismo, textos que resultan particularmente expresivos.

\section{¿QUÉ EXIGE LA IDEA DE UTILIDAD COMO FIN DE LA EDUCACIÓN?}

Para James Mill, uno de los pensadores utilitaristas más importantes, la educación debiera hacer de la mente de cada individuo "en la medida de lo posible un instrumento de la felicidad, primero de la propia y luego también de la de otros seres". Pero la felicidad, comenta Gutmann, es, de seguro, un fin demasiado indeterminado. Es por esto, tal vez, que Bentham propone en su Chrestomathia, su texto clásico sobre educación, un conjunto de fines secundarios que supone son constitutivos de la felicidad futura de cada niño.

La educación debiera entonces proveer a los niños con medios para 1) evitar una "sensualidad desordenada (y sus dañinas consecuencias)", 2) asegurarles empleos que les procuren buenos ingresos, 3) asegurar la admisión a "buenas

2 Como un ejemplo del primer tipo de fundamentación, podría señalarse el artículo de Gerardo Jofré "El sistema de subvenciones en educación: la experiencia chilena”. Estudios Públicos, 1988. Los mejores ejemplos del segundo tipo son los ensayos de Milton Friedman "El rol del gobierno en la educación” en Capitalismo y Libertad, Madrid: RIALP, 1968 y “¿Qué falla en nuestras escuelas?" en Libertad de elegir. Hacia un nuevo liberalismo económico, (con Rose Friedman), México: Grijalbo, 1980, ambos vastamente conocidos en Chile. El informe de la OECD sobre la educación chilena del año 2004 recalca este fuerte sesgo de una ideología del mercado. El Informe del Banco Mundial del año 2008 destaca lo mismo. 
compañías" a partir de las cuales se podría obtener los fines anteriores, 4) evitar el tedio y el "dolor de la vacuidad mental" y 5) "ganar una proporción importante de respeto general".

Observa Amy Gutmann que "si uno acepta la realidad económica prevaleciente... entonces aparentemente los fines de la educación según Bentham son los correctos. Lo que le preocupa es que "los resultados de este razonamiento son incompatibles con el liberalismo". Y esto, porque "una teoría que en principio es neutral en lo que se refiere a una arco muy diverso de modos de vida, resulta ser parcial hacia aquellos modos de vida que producen ingresos altos y aprobación social". El utilitarismo parece ser nos dice Gutmann, "en este sentido no liberal y tener consecuencias conservadoras cuando se aplica a la educación: los niños tendrían que ser educados de manera que puedan encajar bien en la sociedad tal como es"4.

Como lo decía al comenzar, creo que el modelo educacional actual en Chile cabe muy bien en el marco de una concepción utilitarista de este tipo, sobre todo si uno piensa que la educación en nuestro país es pensada fundamentalmente desde la dictadura, en base a finalidades económicas al estilo de los análisis costo/beneficio y, en el caso de la educación superior, en términos de tasas de retorno de la inversión y capital humano.

Según Gutmann, una aproximación a la educación en términos del concepto de libertad es más promisoria y resulta compatible con una función de la educación que va más allá de preparar a los niños y a los estudiantes para ser ciudadanos obedientes de las leyes, buscar su felicidad o escoger ocupaciones.

Aquí hay que aclarar que en las consideraciones que siguen, Amy Gutmann está pensando en el concepto de libertad implícito en lo que podríamos llamar "liberalismo igualitario", y no en el neo-liberalismo, que entiende por libertad, fundamentalmente, la ausencia de coacción por parte del Estado ${ }^{5}$. La educación, nos dice Gutmann, debiera también proveer a los niños habilidades "para concebir y evaluar modos de vida y los sistemas políticos que se les adecúen, que sean diferentes de los que encuentran en su propia sociedad

Jeremy Bentham Chrestomathia, Obras, 1843, Vol. 8.

Amy Gurmann, Art. Cit. Utilitarianism and beyond, Sen y Williams, p. 265.

Ernst Tugendhat, por ejemplo, destaca esta distinción, siguiendo al filósofo Thomas Nagel y precisamente a Amy Gutmann, en su artículo "Liberalismo, libertad y el asunto de los derechos humanos económicos", publicado en su libro Ser-Verdad-Acción. Barcelona: Gedisa, 1998. 
o en cualquier sociedad. Este fin educacional se basa a menudo en la idea de que el conocimiento debiera también buscarse por sí mismo, es decir, en función del desarrollo del intelecto y sus capacidades lógicas e imaginativas".

Según nuestra filósofa, la educación en literatura, historia, antropología y filosofía política (por ejemplo) nos da un tipo de libertad para pensar más allá de las formas establecidas de la vida política y privada. Tal conocimiento es necesario para apreciar completamente y para criticar el sistema político y la elección de modos de vida que hemos heredado. Uno debiera entonces concluir de esto que "este conocimiento es un prerrequisito para ser un buen ciudadano democrático, pero que no es el tipo de conocimiento en base al cual cualquier gobierno democrático existente es probable que dependa para su (mera) supervivencia"'.

Me parece que reflexiones como las de Gutmann son muy necesarias como fundamento para la existencia en la sociedad de saberes críticos como la filosofía y las humanidades. Pero lo son también para permitirnos ver lo que puede ganarse con el uso del saber filosófico para aclarar los propios fines de las instituciones del saber, antes de preocuparnos unilateralmente por su gestión o su rentabilidad.

Como lo dije al comienzo, querría comentar brevemente, para terminar, algunas ideas que desarrolla Martha Nussbaum en su libro El cultivo de la humanidad. Una defensa clásica de la reforma en la educación liberal, de 1997. Sostiene Martha Nussbaum que un "graduado de una universidad o de una escuela superior tiene que ser el tipo de ciudadano capaz de actuar como un participante inteligente en los debates que involucran las diferencias (que se producen en un mundo crecientemente multicultural y multinacional) ya sea como profesional o simplemente como elector, jurado o amigo"7.

En el mundo actual, continúa diciéndonos Nussbaum, esto parece requerir tres habilidades. "La primera es la habilidad para un examen crítico de uno mismo y de las propias tradiciones. (Esto) requiere el desarrollo de la habilidad de razonar lógicamente, de poner a prueba lo que uno lee o dice desde el punto de vista de la solidez del razonamiento, de la exactitud de los hechos 
y la precisión del juicio" ". Es más o menos a lo que se refería Amy Gutmann y que corresponde también al ideal socrático de una vida examinada.

En segundo lugar, sostiene Nussbaum, los ciudadanos necesitan además la capacidad de verse a sí mismos no solo como ciudadanos pertenecientes a alguna región o grupo, sino también y por sobre todo como seres humanos vinculados a los demás seres humanos por lazos de reconocimiento y mutua preocupación..."

Pero me interesa sobre todo la tercera cualidad que subraya Nussbaum y a la que denomina "imaginación narrativa". Dice: "Esto significa la capacidad de pensar cómo sería estar en el lugar de otra persona; ser un lector inteligente de la historia de esa persona, y comprender las emociones, deseos y anhelos que alguien así pudiera experimentar...sí... (la tercera capacidad que nuestros estudiantes deben alcanzar es la de descifrar los significados - de la acción de los demás-mediante la imaginación)" 10 .

En el capítulo en que trata este último tema con más detalle, Nussbaum cita a su vez un hermoso texto de un jurista, Alexander Meiklejohn, en donde este nos dice que: "Existen muchas formas de pensamiento y de expresión, en la amplia gama de manifestaciones humanas, de las cuales el votante deriva el conocimiento, la comprensión y la sensibilidad a los valores humanos, la capacidad de emitir un juicio sano y objetivo que, en lo posible, el voto debería expresar". Y concluye que por esto "el pueblo necesita de las novelas y del teatro, de las pinturas y de los poemas -agregaría tal vez, del cine- "porque será llamado a votar" ${ }^{11}$.

Con esto, ambas autoras defienden la necesidad de las humanidades y la filosofía para la educación, desde una concepción liberal y que está sin duda muy alejada del neoliberalismo actual. Nos queda sin embargo una tarea pendiente, ¿Cómo asegurar, además, el acceso a las humanidades y la filosofía no solo de una élite, sino de estudiantes provenientes de todas las

\footnotetext{
$8 \quad$ Ibíd., p. 29.

Ibíd., p. 30.

Ibíd., p. 31.

Ibíd., p. 121. La autora ha defendido más recientemente, y de una manera notable, este papel crítico de las humanidades frente a las concepciones de la educación y de la formación universitaria que la vinculan unilateralmente con el crecimiento económico y con la formación de competencias funcionales para la producción, en su libro Not for profit. Why democracy needs the humanities, que ha sido traducido de una manera muy actual como Sin fines de lucro. Por qué la democracia necesita de las humanidades.
} 
clases sociales, o, por lo menos, en que la clase social no sea impedimento alguno para el acceso a estos saberes críticos?

Jacques Rancière y Jacques Derrida han hablado últimamente, a propósito de este desafío igualitario, de un "derecho a la filosofía", podríamos decir de un "derecho" igualitario a los saberes críticos.

Naturalmente esto no es tarea de una sola facultad ni tal vez de una sola universidad, sino de un sistema escolar y universitario democrático, de una política educacional pensada desde la democracia y la formación de sujetos democráticos. Pero representa también desafíos muy importantes para nosotros, me parece, en particular en lo que tiene que ver con nuestra concepción de la formación de los profesores, que han de contribuir, a su vez, a la formación de estudiantes críticos y de sujetos democráticos.

\section{BIBLIOGRAFÍA}

Guttman, Amy. "What's the use of going to school", en Amartya Sen y Bernard Williams (comp.). Utilitarianism and beyond. London and Paris, 1982.

Nussbaum, Martha. El cultivo de la humanidad. Una defensa clásica de la reforma en la educación liberal. Santiago: Editorial Andrés Bello, 1997.

Not for profit. Why democracy needs the humanities. New Jersey: Princeton University Press, 2010. 